\title{
Unraveling the ecotoxicity of deep eutectic solvents using the mixture toxicity theory
}

\author{
Inês P.E. Macário ${ }^{a, 1}$, Fátima Jesus ${ }^{a, 1}$, Joana L. Pereira ${ }^{a}$ * , Sónia P.M. Ventura ${ }^{b}$, \\ Ana M.M. Gonçalves ${ }^{\text {a, c }}$, João A.P. Coutinho ${ }^{b}$, Fernando J.M. Gonçalves ${ }^{a}$ \\ a Department of Biology \& CESAM, University of Aveiro, 3810-193 Aveiro, Portugal \\ b CICECO - Aveiro Institute of Materials \& Department of Chemistry, University of Aveiro, 3810-193 Aveiro, Portugal \\ ${ }^{\mathrm{c}}$ MARE, Faculty of Science and Technology, University of Coimbra, 3004-517 Coimbra, Portugal
}

\section{H I G H L I G H T S}

- Mixture toxicity theory successfully assesses the ecotoxicity of $\left[\mathrm{N}_{\mathrm{xxx} x}\right] \mathrm{Cl}$-based DES.

- DES toxicity followed the same trend as salts: $\left[\mathrm{N}_{1111}\right] \mathrm{Cl}<\left[\mathrm{N}_{2222}\right] \mathrm{Cl}<\left[\mathrm{N}_{3333}\right] \mathrm{Cl}$.

- IA model, with specific deviations, adjusted better than CA in 5 out of 6 DES.

- Antagonism was found for [ $\left.\mathrm{N}_{1111}\right] \mathrm{Cl}$-based DES and synergism for [ $\left.\mathrm{N}_{3333}\right] \mathrm{Cl}$-based DES.

- DES toxicity cannot be predicted based solely on the toxicity of HBA and HBD.

\section{A R T I C L E I N F O}

\section{Article history:}

Received 27 June 2018

Received in revised form

28 August 2018

Accepted 29 August 2018

Available online 30 August 2018

Handling Editor: Willie Peijnenburg

\section{Keywords:}

Quaternary ammonium salts

Microtox

Concentration addition

Independent action

Synergism

Antagonism

\begin{abstract}
A B S T R A C T
The interest on deep eutectic solvents (DES) has been increasing. However, the ecotoxicological profile of DES is scarcely known. Also, despite previous studies showed that DES components dissociate in water, none assessed DES toxicity using the classical and adequate models for mixture toxicity prediction concentration addition (CA) and independent action (IA). This study evaluates the ecotoxicological profile of DES based on $\left[\mathrm{N}_{1111}\right] \mathrm{Cl}$, $\left[\mathrm{N}_{2222}\right] \mathrm{Cl}$ and $\left[\mathrm{N}_{3333}\right] \mathrm{Cl}$ as hydrogen bond acceptors (HBA) combined with hydrogen-bond donors (HBD) vis. ethylene glycol and 1-propanol, through the Microtox ${ }^{\circledR}$ Acute Toxicity Test. CA and IA with deviations describing synergism/antagonism, dose-ratio and dose-level effects were fitted to the toxicity data. Neither the starting materials nor DES were found hazardous to Aliivibrio fischeri, in this specific case agreeing with the claimed "green character" of DES. Among the starting materials, ethylene glycol was the least toxic, whereas $\left[\mathrm{N}_{3333}\right] \mathrm{Cl}$ was the most toxic (30 min$\mathrm{EC}_{50}=96.49 \mathrm{~g} \mathrm{~L}^{-1}$ and $0.5456 \mathrm{~g} \mathrm{~L}^{-1}$, respectively). DES toxicity followed the same trend as observed for the salts: $\left[\mathrm{N}_{1111}\right] \mathrm{Cl}$-based DES $<\left[\mathrm{N}_{2222}\right]$ Cl-based DES $<$ [ $\left.\mathrm{N}_{3333}\right]$ Cl-based DES. The IA model, with specific deviations, adjusted better in 5 out of 6 DES. Antagonism was observed for $\left[\mathrm{N}_{1111}\right] \mathrm{Cl}$-based $\mathrm{DES}$, and synergism for [ $\left.\mathrm{N}_{3333}\right] \mathrm{Cl}$-based DES and for 1-propanol: $\left[\mathrm{N}_{2222}\right] \mathrm{Cl}$. The application of the mixture toxicity models represents a breakthrough in the problematic of assessing the toxicity of the countless number of DES that can be created with the same starting materials, since they provide the expected toxicity of any virtual combination between HBA and HBD.
\end{abstract}

(c) 2018 Elsevier Ltd. All rights reserved.

\section{Introduction}

Over the past decades, the design of environmentally friendlier solvents has gained increased attention, driven by global awareness

\footnotetext{
* Corresponding author.

E-mail address: jpereira@ua.pt (J.L. Pereira).

1 Both authors contributed equally.
}

of environmental pollution. Deep eutectic solvents (DES) arose as a new type of tailor-made and "greener" solvents. They are a mixture of two or three components - starting materials (e.g., quaternary ammonium salts, amides, organic acids, polyalcohols), acting as hydrogen bond acceptors (HBA) and hydrogen bond donors (HBD) to form an eutectic mixture based on hydrogen bonding interactions that holds a melting point much lower than either single component (Dai et al., 2013; Ruß and König, 2012; Zhang et al., 
2012). DES are simple to prepare and do not need purification, have low-cost production due to the low cost of starting materials, and have been showing good biocompatibility (Hayyan et al., 2013b; Jhong et al., 2009; Singh et al., 2012).

The DES tailor-made character makes them appealing for several applications within chemistry (Radošević et al., 2015), and pharmaceutical/biomedical (Mbous et al., 2017a) fields. Following their production and use, they can reach aquatic systems, causing toxicity to aquatic biota, hence the recent interest on the toxicity profile of DES. (Eco)toxicity of several $[\mathrm{Chol}] \mathrm{Cl}$ and phosphoniumbased DES was assessed through a variety of organisms (Cardellini et al., 2015; de Morais et al., 2015; Hayyan et al., 2015, 2013a; 2013b; Huang et al., 2014; Juneidi et al., 2016; Radošević et al., 2015; Wen et al., 2015; Zhao et al., 2015), as well as through several cell lines (Hayyan et al., 2016, 2015; Mbous et al., 2017b; Paiva et al., 2014; Radošević et al., 2015).

The assumption of DES low toxicity derives from the low toxicity of their individual components. However, DES components may interact (Hayyan et al., 2013b) depending on their nature and proportion within a DES. According to Hayyan et al. (2013a) and de Morais et al. (2015) the behavior of DES should be closer to that of a single compound, rather than a mixture. However, in presence of water, the assumption that DES structure remains undissociated has been challenged, since water competes for hydrogen bonding (Dai et al., 2015; Hammond et al., 2017; Shah and Mjalli, 2014; Zhekenov et al., 2017). As diluted by more than 50\% in water, DES components indeed dissociate (Dai et al., 2015; Hammond et al., 2017), due to both the disruption of the hydrogen bonding network and to the solvation of the single components by water (Passos et al., 2016). The prevalence of synergistic effects between the starting materials was already suggested (Hayyan et al., 2015, 2013a), but still not quantified. As most (eco)toxicity studies test DES as aqueous solutions comprising two (or more) starting materials, it makes sense to analyse and predict DES toxicity using classical models describing mixtures behavior - concentration addition (CA) and independent action (IA). These models (see material and methods for details) are commonly used to predict the toxicity of a mixture based on the toxicities of its individual components (Backhaus and Faust, 2012).

So far, no rules could be established to predict the (eco)toxicity of DES, which prevents an efficient assessment (mandatory before marketing authorization in most countries) of the countless variations that can be produced for these compounds. The toxic responses seem to depend on DES composition, concentration, and organism tested. This study aims to contribute to the evaluation of the ecotoxicological profile of non-typical DES (e.g. not based on cholinium chloride), using the principles of mixture toxicity theory. The salts tetramethylammonium chloride $\left(\left[\mathrm{N}_{1111}\right] \mathrm{Cl}\right)$, tetraethylammonium chloride $\left(\left[\mathrm{N}_{2222}\right] \mathrm{Cl}\right)$ and tetrapropylammonium chloride $\left(\left[\mathrm{N}_{3333}\right] \mathrm{Cl}\right)$ were used as HBA, whereas ethylene glycol and 1propanol were used as HBD in the preparation of DES. The marine bacteria Aliivibrio fischeri was used as the biological model, and the inhibition of its luminescence was used as the target endpoint through the Microtox ${ }^{\circledR}$ Acute Toxicity Test, a standard, sensitive and widely used ecotoxicological test (Johnson, 2005).

\section{Material and methods}

\subsection{Preparation of DES}

The following chemical compounds were used for the preparation of DES: ethylene glycol (99.5\% purity) and 1-propanol (99.5\% purity), as HBDs; [ $\left.\mathrm{N}_{1111}\right] \mathrm{Cl}$ (97\% purity), [ $\left.\mathrm{N}_{2222}\right] \mathrm{Cl}$ (98\% purity) and $\left[\mathrm{N}_{3333}\right] \mathrm{Cl}$ (98\% purity), as HBAs, at $4 \mathrm{M}$ ratios (HBD:HBA - 1:2, 1:1, $2: 1$ and $4: 1$ ). All chemicals were purchased from Sigma-Aldrich, except 1-propanol, which was purchased from Merck. For the preparation of DES, HBDs and HBAs were added gravimetrically to a closed vial and heated in a heat block with constant agitation with a known volume of water. As a transparent liquid formed, the mixture was cooled down to room temperature. Water content of the starting materials was determined by Karl Fischer titration, and was taken into account in the calculation of $\mathrm{EC}_{x}$ values.

\subsection{Microtox $^{\circledR}$ Toxicity Test assay}

DES were tested using the Microtox ${ }^{\circledR}$ Toxicity Test (see Johnson, 2005), through the inhibition of the luminescence in the marine bacteria A. fischeri. Briefly, the bacteria were exposed to a range of diluted solutions (from 0 to $81.9 \%$ ) of each DES or each starting material prepared in ultra-pure water. The concentrations of these stocks were adjusted to capture full breadth concentrationresponse curves in the tests. These standard dilutions were made following the manufacturer protocol with the supplied diluent reagent $(2 \% \mathrm{NaCl}$ solution in water), after a first step of osmotic pressure adjustment of the samples to $2 \% \mathrm{NaCl}$ using the proprietary osmotic adjusting solution; this ensures that the test is run at optimal osmotic conditions for the bacteria, i.e. $2 \% \mathrm{NaCl}$ (Johnson, 2005). Measurements of the luminescent output of the bacteria were recorded and compared with the light output of a control sample (bacteria in blank diluent) after 5,15 , and 30 min of exposure. These data were used to estimate the concentrations eliciting $50 \%, 20 \%$ and $10 \%$ luminescence inhibition $\left(\mathrm{EC}_{50}, \mathrm{EC}_{20}\right.$ and $\mathrm{EC}_{10}$, respectively) and the corresponding 95\% confidence intervals through a non-linear regression, using the least-squares method to fit the data to the logistic equation. Despite calculated directly based on tested mass-per-volume concentrations, these EC $x$ benchmarks estimated for starting materials and DES, are potentially useful information to include in risk assessment databases as required by different regulatory frameworks (e.g. European Union REACH Directive EC 1907/2006).

\subsection{Mixtures toxicity assessment and modelling}

The data were analysed on the basis of the mixture toxicity theory, which stems from the application of the baseline CA and IA models.

The CA model relies on the assumption that the components of a mixture have the same site of action (bind to the same biological receptor) in organisms. Thus, each component acts as dilutions of each other (Altenburger et al., 2000). This means that the effect can be predicted by replacing one component totally or in part by the equieffective amount of another component. For a mixture of $n$ components, the CA concept can be mathematically expressed as:

$$
\sum_{i=1}^{n} \frac{c_{i}}{E C x_{i}}=1
$$

where $c_{i}$ denotes the concentration (or dose) of the ith component which causes $\mathrm{x} \%$ of total effect and $\mathrm{ECX}_{\mathrm{i}}$ represents the concentration of that substance causing $\mathrm{x} \%$ of effect if applied singly (Backhaus and Faust, 2012). Each fraction $\mathrm{c}_{\mathrm{i}} / \mathrm{ECX}_{\mathrm{i}}$ is termed a "toxic unit" (TU) and represents the concentration of the ith component in the mixture scaled for its relative potency (Backhaus and Faust, 2012).

The model IA assumes that mixture components act on different sites of action of an organism (Altenburger et al., 2000). Thus, the effect of a component is independent of the other. For a mixture of $n$ components, the expected effect can be predicted according to the joint probability of statistically independent events following the 
equation:

$E\left(C_{\text {mix }}\right)=1-\prod_{i=1}^{n}\left(1-E\left(C_{i}\right)\right)$

where $E\left(C_{\text {mix }}\right)$ denotes the expected effect of the mixture (scaled $0-1) ; E\left(C_{i}\right)$ denotes the effect of component $i$ if applied singly, and $C_{i}$ is the concentration of that component in the mixture (Altenburger et al., 2000).

The application of both models is limited by the assumption that all mixture components affect the same endpoint (e.g. mortality, growth, reproduction) and that there are no interactions between the mixture components, concerning uptake, distribution or metabolization. By characterizing the deviation of experimental data to these reference models, one can assess interactions between mixture components and define corresponding synergic and antagonistic behavior. This was done in the present study as follows.

The experimental responses to all combinations between starting materials within each DES (different molar ratios between starting materials were pooled) along with the responses (bioluminescence inhibition) to each corresponding starting material dosed singly were used to feed mixtures response surface modelling for each DES. First, inhibitory experimental records were fitted to the nonlinear decay model representing toxicological concentration-response curves (Barata et al., 2006). Significant fitting was always achieved, with model accuracy being assessed through adjusted coefficient of determination $\left(\mathrm{r}^{2}\right)$ and residual distribution (Quinn and Keough, 2002). The significance of regressions and their regression coefficients were determined by the F-test of overall significance and the $t$-test, respectively. Then, the joint action within each DES was assessed by fitting the experimental data into the reference mixture models of CA and IA, as well as to CA and IA models added the deviation functions allowing the assessment of synergic/antagonist effect, dose-level and dose-ratio dependent effects; such effects are denoted by two parameters defining the functional form of the deviation pattern, $a$ and $b$, as described in Jonker et al. (2005). Mixture toxicity modelling and analysis was run in a customised $\mathrm{MS}^{\circledR}$ Excel $^{\circledR}$ spreadsheet (ToxCalcMix, version 1.0, last rev. 19/03/2018; @Prof. António J.A. Nogueira). Contour plots showing the interactive effects between HBA and HBD within each DES towards A. fischeri were created to facilitate interpretation. Several statistic parameters were determined to allow comparison of the model-deviation fit (Jonker et al., 2005; Motulsky and Christopoulos, 2004; Quinn and Keough, 2002): $r^{2}$ (coefficient of determination), RMSD (root-mean-square deviation), SSE (sum of squared errors), AIC (Akaike's information criterion) and the $p$-value for the F-test. RMSD provides a measure of the prediction precision through the differences between predicted and observed values. Both for RMSD and SSE, lower values stand for better fit. AIC allows the comparison of the adequacy of multiple models, with a lower AIC value denoting higher likelihood of the model. The $p$ (F-test) stands for the $p$-value of the F-test applied to the errors of each model-deviation, which tests the null hypothesis that the errors of respective deviation are equal or higher than the errors of other deviations - we applied the F-test to compare the errors of each deviation with the errors of the baseline model and other deviations with less fitting parameters. $P$-values $\leq$ 0.05 mean that the respective model-deviation allows a better adjustment to the experimental data.

\section{Results and discussion}

The interest on DES has increased in the last years, boosted by their advantages over other solvents (Vieira et al., 2018). This interest has been accompanied by an increasing number of studies on their toxicity. However, the majority of theses studies used the salt [Chol]Cl as HBA, and considered each DES as a single compound, which does not dissociate, regardless the presence of water. Following a different approach, in this study we consider the DES aqueous solutions as a mixture, and aimed to evaluate the applicability of the mixture theory models to the understanding and prediction of the toxicity of DES based on non conventional HBA.

It has been argued that DES can exert their toxicity to bacteria by disrupting the cell wall (Wen et al., 2015). The cell wall in gram negative bacteria such as $A$. fischeri possesses molecules of peptidoglycan outside of the cytoplasmatic membrane, which are responsible for the rigidity and strength of the structure (Nelson and Cox, 2012). Since DES were tested as aqueous solutions, they are expected to be dissociated (Dai et al., 2015; Hammond et al., 2017; Passos et al., 2016; Zhekenov et al., 2017). In this context, the ammonium cation could behave similarly to the cholinium cation addressed in other studies, by interacting with the polysaccharides or the peptide chains through hydrogen bonding or electrostatic interactions, leading to distortion or disruption of the cell wall (Wen et al., 2015). Moreover, the saltwater test media of the Microtox ${ }^{\circledR}$ test, rich in chloride, can play an important role in the results, since chloride can also interact with the DES cations, reducing their permeability through the cell walls and, therefore, their toxicity (Latała et al., 2005).

The median effective concentrations $\left(E_{50}\right)$ as estimated following 5, 15 and $30 \mathrm{~min}$ of exposure of A. fischeri to each HBA, HBD and DES are presented in Table 1. There was a general agreement in the benchmarks estimated for different exposure periods; despite this, very slight fluctuations were observed through time with little meaning since they lead to overlapping confidence intervals (thus rendering the benchmarks unlikely to be different between exposure periods). Because a longer exposure period (30 min) is likely to better ensure that the whole bacteria inoculum in each treatment contacts and/or internalizes the waterborne chemicals, further comparative discussion regarding $\mathrm{EC}_{50}$ benchmarks will be based on the results retrieved following $30 \mathrm{~min}$ of exposure. For a complete characterization of these starting materials and eutectic mixtures, all calculated $\mathrm{EC}_{x}$ values after $30 \mathrm{~min}$ of exposure are presented as supplementary material (Table S1).

According to the United Nations Globally Harmonized System of Classification and Labelling Chemicals (GHS) (UN, 2011) none of the starting materials, neither DES, could be considered hazardous to the aquatic environment, as their 30 min- $\mathrm{EC}_{50}$ values are above $100 \mathrm{mg} \mathrm{L}^{-1}$. Such a low toxicity agrees with the claimed "green character" of DES. Among the starting materials, ethylene glycol was the least toxic $\left(30 \mathrm{~min}-\mathrm{EC}_{50}=96.49 \mathrm{~g} \mathrm{~L}^{-1}\right)$, whereas $\left[\mathrm{N}_{3333}\right] \mathrm{Cl}$ was the most toxic $\left(30\right.$ min-EC $\left.50=0.5456 \mathrm{~g} \mathrm{~L}^{-1}\right)$. Regarding the toxicity of HBDs, the lower toxicity of ethylene glycol compared to 1-propanol reflects its lower lipophilicity, represented by its lower $\log \mathrm{P}$ (logarithm function of 1-octanol/water partition coefficient; $\log \mathrm{P}=-1.36$ and 0.25 respectively for ethylene glycol and 1propanol; Chemspider, assessed on 19 january 2018). Previous studies also found lower toxicity of ethylene glycol compared to other HBDs such as glycerine, tryethylene glycol, urea, acetamide and glycerol (Hayyan et al., 2013b; Wen et al., 2015). Concerning the toxicity of the tested HBAs, it increased in the following order: $\left[\mathrm{N}_{1111}\right] \mathrm{Cl}<\left[\mathrm{N}_{2222}\right] \mathrm{Cl}<\left[\mathrm{N}_{3333}\right] \mathrm{Cl}$. This variation agrees with the sidechain effect defining increased toxicity along with the alkyl side chain elongation (Egorova and Ananikov, 2014; Matzke et al., 2010). This effect could be attributed to the increased lipophilicity caused by the elongation of the alkyl chain, with consequent higher reactivity with the biological membranes and embedded proteins (Stolte et al., 2007). It was found valid both for DES with ethylene 
Table 1

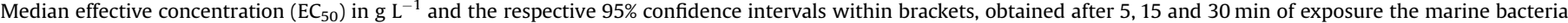
A. fischeri (Microtox ${ }^{\circledR}$ toxicity test) to different DES and their starting materials.

\begin{tabular}{|c|c|c|c|c|}
\hline & Chemical compounds & $5 \mathrm{~min}-\mathrm{EC}_{50}(95 \% \mathrm{CI}), \mathrm{g} \mathrm{L}^{-1}$ & $15 \min -\mathrm{EC}_{50}(95 \% \mathrm{CI}), \mathrm{g} \mathrm{L}^{-1}$ & $30 \mathrm{~min}-\mathrm{EC}_{50}(95 \% \mathrm{CI}), \mathrm{g} \mathrm{L}^{-1}$ \\
\hline \multirow[t]{5}{*}{ Starting materials } & {$\left[\mathrm{N}_{1111}\right] \mathrm{Cl}$} & $23.79(19.37-28.21)$ & $20.88(16.64-25.13)$ & $22.69(17.48-27.90)$ \\
\hline & {$\left[\mathrm{N}_{2222}\right] \mathrm{Cl}$} & $17.78(12.94-22.62)$ & $18.45(12.482-24.421)$ & $19.24(13.27-25.21)$ \\
\hline & {$\left[\mathrm{N}_{3333}\right] \mathrm{Cl}$} & $0.3800(0.3454-0.4146)$ & $0.4706(0.4224-0.5187)$ & $0.5456(0.4870-0.6040)$ \\
\hline & 1-propanol & $8.327(6.951-9.703)$ & $9158.993(7.788-10.53)$ & $9.052(7.475-10.63)$ \\
\hline & Ethylene glycol & $77.12(52.16-102.08)$ & $87.75(62.74-112.8)$ & $96.49(69.96-123.0)$ \\
\hline \multirow[t]{23}{*}{ DES } & 1-propanol:[N $\left.\mathrm{N}_{1111}\right] \mathrm{Cl} 1: 1$ & $20.46(17.14-23.78)$ & $19.93(17.62-22.23)$ & $20.87(16.92-24.81)$ \\
\hline & 1-propanol:[N $\left[\mathrm{N}_{1111}\right] \mathrm{Cl} 2: 1$ & $15.43(11.77-19.10)$ & $15.42(11.74-19.10)$ & $16.15(12.10-20.19)$ \\
\hline & 1-propanol:[N(1111 $] \mathrm{Cl} 4: 1$ & $15.68(12.87-18.49)$ & $16.43(14.71-18.14)$ & $15.36(14.00-16.71)$ \\
\hline & 1-propanol:[$\left[\mathrm{N}_{2222}\right] \mathrm{Cl} 1: 2$ & $19.53(16.58-33.47)$ & $20.71(17.51-23.92)$ & $22.26(19.15-25.36)$ \\
\hline & 1-propanol:[N $\left.\mathrm{N}_{2222}\right] \mathrm{Cl} 1: 1$ & $17.20(11.82-22.95)$ & $17.59(12.45-22.73)$ & $18.09(13.44-22.74)$ \\
\hline & 1-propanol:[$\left[\mathrm{N}_{2222}\right] \mathrm{Cl} 2: 1$ & $12.51(10.66-14.37)$ & $13.86(11.61-16.12)$ & $15.55(12.80-18.30)$ \\
\hline & 1-propanol:[$\left[\mathrm{N}_{2222}\right] \mathrm{Cl} 4: 1$ & 7.821 (6.525-9.117) & $8.571(7.673-9.470)$ & $9.500(8.555-10.44)$ \\
\hline & 1-propanol:[N $\left.\mathrm{N}_{3333}\right] \mathrm{Cl} 1: 2$ & $0.8187(0.6186-1.019)$ & $1.467(1.139-1.795)$ & 1.555 (1.181-1.929) \\
\hline & 1-propanol:[N $\left.\mathrm{N}_{3333}\right] \mathrm{Cl} 1: 1$ & $10.94(7.172-14.70)$ & $6.106(3.756-8.455)$ & $4.981(2.862-7.099)$ \\
\hline & 1-propanol:[$\left[\mathrm{N}_{3333}\right] \mathrm{Cl} 2: 1$ & $1.415(1.207-1.622)$ & $1.700(1.490-1.910)$ & $1.845(1.618-2.072)$ \\
\hline & 1-propanol:[N $\left.\mathrm{N}_{3333}\right] \mathrm{Cl} 4: 1$ & $0.8254(0.6444-1.006)$ & $0.9896(0.8050-1.174)$ & $1.120(0.9055-1.334)$ \\
\hline & Ethylene glycol:[ $\left.\mathrm{N}_{1111}\right] \mathrm{Cl} 1: 2$ & $31.73(28.97-34.49)$ & $29.01(26.38-31.63)$ & $30.20(20.59-33.34)$ \\
\hline & Ethylene glycol:[ $\left.\mathrm{N}_{1111}\right] \mathrm{Cl} 1: 1$ & $55.72(50.02-61.41)$ & $52.11(46.79-57.43)$ & $53.99(47.88-60.09)$ \\
\hline & Ethylene glycol:[ $\left.\mathrm{N}_{1111}\right] \mathrm{Cl} 2: 1$ & $42.35(37.62-47.07)$ & $42.41(38.81-45.99)$ & $49.25(46.47-52.03)$ \\
\hline & Ethylene glycol:[ $\left.\mathrm{N}_{1111}\right] \mathrm{Cl} 4: 1$ & $52.78(35.46-70.10)$ & $54.52(37.55-71.49)$ & $65.62(47.36-83.88)$ \\
\hline & Ethylene glycol:[ $\left.\mathrm{N}_{2222}\right] \mathrm{Cl} 1: 2$ & $18.20(14.66-21.74)$ & $18.98(15.36-22.60)$ & $18.93(15.27-22.60)$ \\
\hline & Ethylene glycol:[ $\left.\mathrm{N}_{2222}\right] \mathrm{Cl} 1: 1$ & $23.91(21.54-26.29)$ & $24.50(21.19-27.81)$ & $23.94(20.52-27.36)$ \\
\hline & Ethylene glycol:[ $\left[\mathrm{N}_{2222}\right] \mathrm{Cl} 2: 1$ & $21.52(14.21-28.82)$ & $9.069(8.882-9.257)$ & $18.61(13.75-23.48)$ \\
\hline & Ethylene glycol:[ $\left.\mathrm{N}_{2222}\right] \mathrm{Cl} 4: 1$ & $35.31(27.59-43.03)$ & $37.18(27.65-46.72)$ & $36.39(27.79-44.99)$ \\
\hline & Ethylene glycol:[ $\left[\mathrm{N}_{333}\right] \mathrm{Cl} 1: 2$ & $0.5362(0.5080-0.5644)$ & $0.7786(0.7100-0.8472)$ & $0.9713(0.7336-1.209)$ \\
\hline & Ethylene glycol:[ $\left.\mathrm{N}_{3333}\right] \mathrm{Cl} 1: 1$ & $2.520(2.417-2.624)$ & $3.074(2.949-3.199)$ & $3.665(3.441-3.888)$ \\
\hline & Ethylene glycol:[ $\left[\mathrm{N}_{3333}\right] \mathrm{Cl} 2: 1$ & $0.7399(0.6639-0.8138)$ & $0.9087(0.8042-1.013)$ & $0.9453(0.8259-1.064)$ \\
\hline & Ethylene glycol:[ $\left[\mathrm{N}_{3333}\right] \mathrm{Cl} 4: 1$ & $1.052(0.9616-1.143)$ & $1.273(1.163-1.384)$ & $1.285(1.142-1.429)$ \\
\hline
\end{tabular}

glycol, as with 1-propanol, and highlights the central role of HBA in DES toxicity.

The effects of the binary mixtures HBD:HBA to A. fischeri are depicted in Fig. 1 through 2D isobolographic diagrams representing response surfaces. In addition, estimated parameters for the fitting of experimental data to the reference mixture models and the corresponding deviation functions are shown in Table 2. The interpretation of such parameters to appraise the behavior of each mixture (i.e. each DES) was performed based on Jonker et al. (2005).

Regarding the toxicity of the DES composed of 1propanol:[ $\left.\mathrm{N}_{1111}\right] \mathrm{Cl}$, only the $\mathrm{CA}$ model incorporating dose-level deviation showed significant fitting trough the F-test $(p=0.039)$; also, this deviation has high $\mathrm{r}^{2}$ values and low SSE and RMSD values (Table 2) and, thus, can be considered as the model that best describes the experimental toxicity data. The positive value of "a" indicates antagonism at low dose level and synergism at high dose level. Graphically, the antagonism is evident through the convex shape of the isobologram (Fig. 1A). The theoretical shift between antagonism and synergism occurs at higher dose level than the $\mathrm{EC}_{50}$ value, as given by the " $\mathrm{b}_{\mathrm{DL}}$ " value $(0.322$, Table 2$)$, and shown by the approximation to linearity of the isobole denoting $80 \%$ luminescence inhibition compared to the control (i.e. the $20 \%$ luminescence isobole in Fig. $1 \mathrm{~A}$ ) while that denoting $40 \%$ of luminescence isobole still presents the typical convex shape defining antagonism. The linearity of the isobole for $20 \%$ luminescence (approximating to a baseline CA behavior where chemicals do not interact) is indicative that the full inversion into a synergic behavior of the mixture is unlikely to occur in practice or that its occurrence may occur at very high effect levels (higher than $80 \%$ luminescence inhibition compared to the control) that may not be biologically significant as the predictions may confirm beyond $100 \%$ luminescence inhibition.

All the deviation functions from IA and CA fitted significantly better than the baseline models in the case of ethylene glycol: $\left[\mathrm{N}_{1111}\right] \mathrm{Cl}$, with dose-level and dose-ratio dependence bearing higher error than $\mathrm{S} / \mathrm{A}$ in both cases (P-value from the $\mathrm{F}$ test $<0.05$; Table 2). This supports the assumption that this mixture behaves according to the S/A model. This is the simpler among the deviation-models explaining the data better than the corresponding baseline (CA or IA) and explaining the data at least as well as DL or DR, this reasoning preventing overfitting effects and the hampering of predictive accuracy ('Principle of Parsimony'; Burnham and Anderson, 2002). Concerning whether CA-S/A or IA$\mathrm{S} / \mathrm{A}$ fit better, given that IA-S/A model shows higher $\mathrm{r}^{2}$ and lower SSE, RMSD and AIC values compared to CA-S/A, one should reasonably assume that IA-S/A is the model best describing this mixture's behavior. The positive value of "a" indicates antagonism, which agrees with the slightly convex shape of the isobologram (Fig. 1B). Antagonism is more evident at low dose level, whereas a tendency for baseline IA behavior or slight synergism is observed at high dose level, as suggested by the "a" value in the DL deviation and retrievable from the isobologram in Fig. 1B. Antagonism is mainly caused by the salt, as given by the positive value of $b_{\mathrm{HBA}}$, whereas synergism is mainly caused by ethylene glycol, as given by the negative value of $\mathrm{b}_{\mathrm{HBD}}$.

For 1-propanol: $\left[\mathrm{N}_{2222}\right] \mathrm{Cl}$, a good fitting to the experimental data was achieved by the IA model, with all the deviation functions adjusting better than the baseline model (Table 2). However, the Ftest values show that neither the DL deviation nor the DR deviation fit better than the S/A deviation, which suggests that the model IA with S/A deviation is the most appropriate to describe the experimental data and hence the toxic behavior of the mixture towards A. fischeri. The negative "a" value of the S/A deviation indicates synergism, which agrees with the slightly concave shape of the response curve (Fig. 1C).

Similarly to 1-propanol: $\left[\mathrm{N}_{2222}\right] \mathrm{Cl}$, the CA model and derived deviation models did not fit significantly to the experimental data, and a good fitting of the experimental data to the IA model with all deviations was achieved for ethylene glycol: $\left[\mathrm{N}_{2222}\right] \mathrm{Cl}$. Indeed, the $p$-values of the F-test suggest that all the deviations to IA adjust 

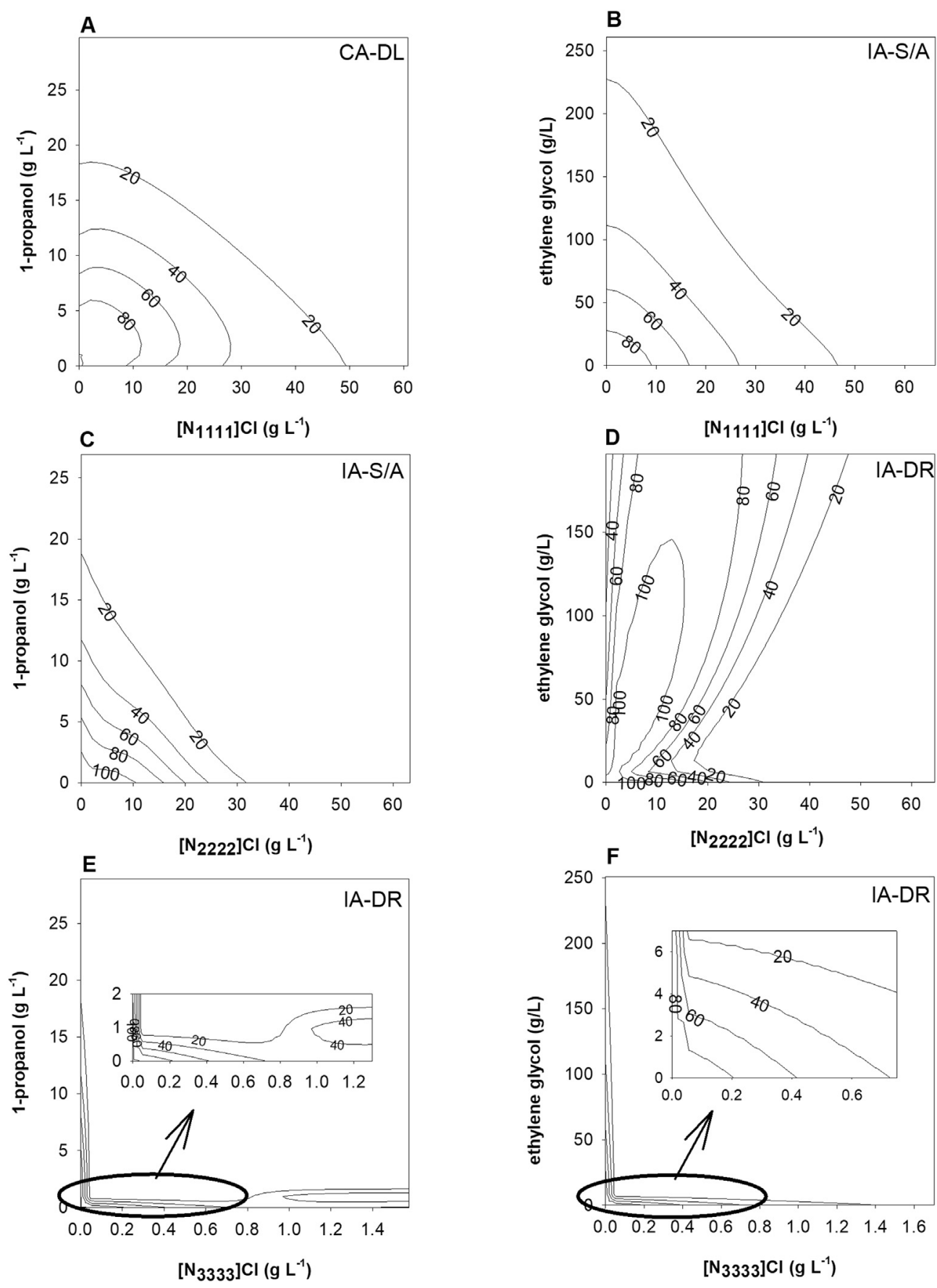

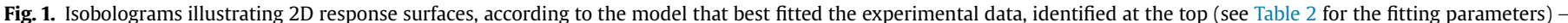

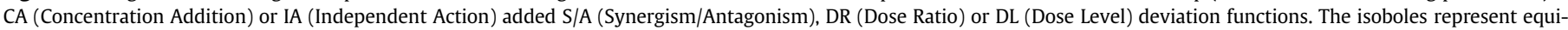
effective levels, the effect being bioluminescence of the bacteria $A$. fischeri relative to control levels.

better that the baseline model. Then, although IA-DR is the most complex among the three deviation models (thus failing to fully comply with the best practices for regression modelling; Burnham and Anderson, 2002), integrative analysis of the statistics suggests that this is the most adequate to predict the behavior of the present mixture. IA-DR explains the data better than S/A $(\mathrm{P}<0.05$ for the direct comparison of the errors; Table 2) but this is not the case while comparing with IA-DL $(\mathrm{P}>0.05$; Table 2$)$. However, IA-DR bears a relevant increase in $r^{2}$, SSE, RMSD and AIC compared to IA-DL, strongly suggesting that the DR deviation indeed fits better to the data. The value of "a" indicates antagonism, which is mainly due to ethylene glycol (" $\mathrm{bHBD}_{\mathrm{HBD}}$ ), as observed in the isobologram (Fig. 1D); also, synergism is observed, being mainly caused by the salt $\left[\mathrm{N}_{2222}\right] \mathrm{Cl}$, as given by the " $\mathrm{b}_{\text {HBA }}$ " value. Because the DL deviation also reflects very well the mixture behavior, it is worth remarking that synergism mostly occurs at low dose levels while antagonism may establish at high dose level (negative value of the corresponding "a” parameter of -5.064 ).

Concerning the DES based in 1-propanol:[ $\left[\mathrm{N}_{3333}\right] \mathrm{Cl}$, both the $\mathrm{CA}$ and IA models with dose-ratio deviations adjusted significantly to the observed toxicity. However, given the lower SSE values associated to IA with DR deviation, it is reasonable to assume that IA-DR 
Table 2

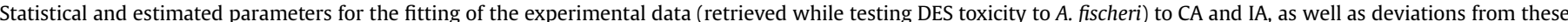

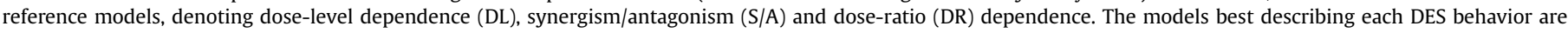

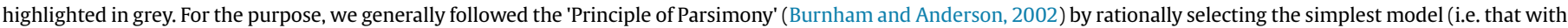
lower number of added parameters) that significantly fitted de dataset with equal and/or lower uncertainty.

\begin{tabular}{|c|c|c|c|c|c|c|c|c|c|}
\hline & & \multicolumn{4}{|c|}{$\mathbf{C A}$} & \multicolumn{4}{|c|}{ IA } \\
\hline & & Baseline & S/A & DL & DR & Baseline & $\mathbf{S} / \mathbf{A}$ & DL & DR \\
\hline 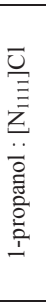 & $\begin{array}{l}\mathrm{r}^{2} \\
\text { RMSD } \\
\text { SSE (df) } \\
\text { AIC } \\
\text { P (F-test) }\end{array}$ & $\begin{array}{l}0.926 \\
- \\
3644.292(21) \\
183.257 \\
-\end{array}$ & $\begin{array}{l}0.963 \\
8.335 \\
1806.420 \\
132.821 \\
\text { vs CA: } 0.075 \\
\\
a=3.151\end{array}$ & $\begin{array}{l}0.970 \\
7.686 \\
1476.823 \\
131.249 \\
\text { vs CA: } \mathbf{0 . 0 3 9} \\
\text { vs S/A: } 0.373 \\
\mathrm{a}=6.167 \\
\mathrm{~b}_{\mathrm{DL}}=0.322\end{array}$ & $\begin{array}{l}0.964 \\
8.656 \\
1798.281 \\
140.840 \\
\text { vs CA: } 0.111 ; \\
\text { vs S/A: } 0.589 ; \\
\text { vs DL: } 0.296 \\
\mathrm{a}=1.941 ; \\
\mathrm{b} 1=1.950 ; \\
\mathrm{b} 2=-0.009\end{array}$ & $\begin{array}{l}0.957 \\
- \\
2115.481(21) \\
133.571 \\
-\end{array}$ & $\begin{array}{l}0.969 \\
7.653 \\
1522.746 \\
128.209 \\
\text { vs IA: } 0.267\end{array}$ & $\begin{array}{l}0.971 \\
7.626 \\
1453.730 \\
130.823 \\
\text { vs IA: } 0.271 \\
\text { vs S/A: } 0.506 \\
a=2.140 \\
b_{D L}=0.834\end{array}$ & $\begin{array}{l}0.969 \\
7.960 \\
1520.648 \\
136.312 \\
\text { vs IA: } 0.349 ; \\
\text { vs S/A: } 0.592 \text {; } \\
\text { vs DL: } 0.415 \\
\text { a }=0.729 ; \\
\text { b1 }=0.691 ; \\
\text { b2 }=0.037\end{array}$ \\
\hline 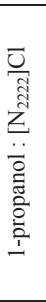 & $\begin{array}{l}\mathrm{r}^{2} \\
\text { RMSD } \\
\text { SSE (df) } \\
\text { AIC } \\
\text { P (F-test) }\end{array}$ & $\begin{array}{l}0.942 \\
- \\
3854.525(29) \\
179.356 \\
-\end{array}$ & $\begin{array}{l}0.942 \\
10.590 \\
3813.406 \\
182.045 \\
\text { vs CA: } 0.527 \\
a=-0.496\end{array}$ & $\begin{array}{l}0.948 \\
10.232 \\
3454.843 \\
181.869 \\
\text { vs CA: } 0.461 ; \\
\text { vs } \mathrm{S} / \mathrm{A}: 0.437 \\
\mathrm{a}=-2.091 \\
\mathrm{~b}_{\mathrm{DL}}=0.629\end{array}$ & $\begin{array}{l}0.962 \\
8.887 \\
2527.494 \\
174.454 \\
\text { vs CA: } 0.205 \\
\text { vs S/A: } 0.195 ; \\
\text { vs DL: } 0.757 \\
\mathrm{a}=-0.817 \\
\mathrm{~b}_{1}=-11.784 \\
\mathrm{~b}_{2}=10.967 ; 2\end{array}$ & $\begin{array}{l}0.898 \\
- \\
6695.802(29) \\
198.686 \\
- \\
-\end{array}$ & $\begin{array}{l}0.958 \\
9.031 \\
2772.774 \\
170.891 \\
\text { vs IA: } \mathbf{0 . 0 1 4} \\
\\
a=-2.761\end{array}$ & $\begin{array}{l}0.971 \\
7.653 \\
1932.601 \\
161.537 \\
\text { vs IA: 0.001; } \\
\text { vs S/A: } 0.201 \\
a=-3.980 \\
b_{D L}=1.129\end{array}$ & $\begin{array}{l}0.972 \\
7.583 \\
1840.151 \\
163.346 \\
\text { vs IA: 0.001; } \\
\text { vs S/A: } 0.196 \text {; } \\
\text { vs DL: } 0.510 \\
\mathrm{a}=-1.935 ; \\
\mathrm{b}_{1}=-6.408 ; \\
\mathrm{b}_{2}=4.473\end{array}$ \\
\hline 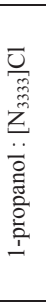 & $\begin{array}{l}\mathrm{r}^{2} \\
\text { RMSD } \\
\text { SSE (df) } \\
\text { AIC } \\
\text { P (F-test) } \\
\text { a, b }\end{array}$ & $\begin{array}{l}0.675 \\
- \\
15601.085(30) \\
233.286\end{array}$ & $\begin{array}{l}0.726 \\
19.396 \\
13166.800 \\
230.203 \\
\text { vs CA: } 0.358 \\
a=20.915\end{array}$ & $\begin{array}{l}0.727 \\
19.656 \\
13136.099 \\
233.351 \\
\text { vs CA: } 0.392 ; \\
\text { vs S/A: } 0.535 \\
a=19.124 \\
b_{D L}=-0.0273\end{array}$ & $\begin{array}{l}0.905 \\
11.752 \\
4557.887 \\
198.708 \\
\text { vs CA: 0.002; } \\
\text { vs S/A: 0.006; } \\
\text { vs DL: } 0.995 \\
a=-819.580 \\
b_{1}=-1792.308 \\
b_{2}=972.731\end{array}$ & $\begin{array}{l}0.683 \\
- \\
15232.321(30) \\
232.425 \\
- \\
-\end{array}$ & $\begin{array}{l}0.728 \\
19.318 \\
13061.693 \\
229.914 \\
\text { vs IA: } 0.374\end{array}$ & $\begin{array}{l}0.733 \\
19.433 \\
12840.183 \\
232.531 \\
\text { vs IA: } 0.393 \\
\text { vs S/A: } 0.520 \\
a=1.517 \\
b_{D L}=-9.364\end{array}$ & $\begin{array}{l}0.909 \\
11.517 \\
4377.147 \\
197.251 \\
\text { vs IA: 0.001; } \\
\text { vs S/A: } \mathbf{0 . 0 0 5} \text {; } \\
\text { vs DL: } 0.996 \\
a=-468.005 ; \\
b_{1}=-1022.536 \\
b_{2}=554.532\end{array}$ \\
\hline 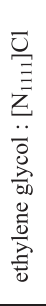 & $\begin{array}{l}\mathrm{r}^{2} \\
\text { RMSD } \\
\text { SSE (df) } \\
\text { AIC } \\
\text { P (F-test) } \\
\text { a, b }\end{array}$ & $\begin{array}{l}0.935 \\
- \\
3886.956(30) \\
183.257 \\
- \\
\\
-\end{array}$ & $\begin{array}{l}0.976 \\
6.353 \\
1412.460 \\
149.838 \\
\text { vs CA: } \mathbf{0 . 0 0 5} \\
\\
a=4.171\end{array}$ & $\begin{array}{l}0.981 \\
5.814 \\
1149.468 \\
145.653 \\
\text { vs CA: 0.001; } \\
\text { vs S/A: } 0.327 \\
\mathrm{a}=6.668 ; \\
\mathrm{b}_{\mathrm{DL}}=0.192\end{array}$ & $\begin{array}{l}0.982 \\
5.754 \\
1092.750 \\
147.294 \\
\text { vs CA: 0.001; } \\
\text { vs S/A: } 0.316 \\
\text { vs DL: } 0.514 \\
\mathrm{a}=0.519 \\
\mathrm{~b}_{1}=-7.587 \\
\mathrm{~b}_{2}=8.106\end{array}$ & $\begin{array}{l}0.948 \\
- \\
3066.528(30) \\
174.722 \\
-\end{array}$ & $\begin{array}{l}0.981 \\
5.688 \\
1132.290 \\
141.879 \\
\text { vs IA: } \mathbf{0 . 0 0 6} \\
\mathrm{a}=2.436\end{array}$ & $\begin{array}{l}0.981 \\
5.744 \\
1121.839 \\
144.777 \\
\text { vs IA: } 0.007 \\
\text { vs S/A: } 0.528 \\
a=2.972 \\
\mathrm{~b}_{\mathrm{DL}}=0.276\end{array}$ & $\begin{array}{l}0.985 \\
5.233 \\
903.835 \\
140.461 \\
\text { vs IA: 0.002; } \\
\text { vs S/A: } 0.345 ; \\
\text { vs DL: } 0.679 \\
\mathrm{a}=0.338 \\
\mathrm{~b}_{1}=-4.134 \\
\mathrm{~b}_{2}=4.472\end{array}$ \\
\hline 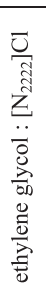 & $\begin{array}{l}\mathrm{r}^{2} \\
\text { RMSD } \\
\text { SSE (df) } \\
\text { AIC } \\
\text { P (F-test) } \\
\text { a, b }\end{array}$ & $\begin{array}{l}0.846 \\
- \\
8945.590(30) \\
213.264 \\
-\end{array}$ & $\begin{array}{l}0.888 \\
13.632 \\
6503.988 \\
204.813 \\
\text { vs CA: } 0.223 \\
a=-6.552\end{array}$ & $\begin{array}{l}0.892 \\
13.578 \\
6267.991 \\
206.714 \\
\text { vs CA: } 0.221 ; \\
\text { vs S/A: } 0.499 \\
a=-8.027 \\
b_{D L}=-0.249\end{array}$ & $\begin{array}{l}0.914 \\
12.329 \\
5016.368 \\
202.159 \\
\text { vs CA: } 0.103 ; \\
\text { vs S/A: } 0.313 \\
\text { vs DL: } 0.685 \\
a=5.794 ; \\
b_{1}=34.438 \\
b_{2}=-28.644\end{array}$ & $\begin{array}{l}0.836 \\
- \\
9522.147(30) \\
215.512 \\
-\end{array}$ & $\begin{array}{l}0.921 \\
11.419 \\
4563.918 \\
192.060 \\
\text { vs IA: } \mathbf{0 . 0 3 1} \\
a=-4.387\end{array}$ & $\begin{array}{l}0.926 \\
11.282 \\
4327.335 \\
193.376 \\
\text { vs IA: 0.028; } \\
\text { vs S/A: } 0.482 \\
\mathrm{a}=-5.064 \\
\mathrm{~b}_{\mathrm{DL}}=0.824\end{array}$ & $\begin{array}{l}0.964 \\
8.011 \\
2117.875 \\
171.116 \\
\text { vs IA: } \mathbf{0 . 0 0 0} \\
\text { vs S/A: } \mathbf{0 . 0 3 6} \\
\text { vs DL: } 0.959 \\
a=2.231 ; \\
b_{1}=18.345 \\
b_{2}=-16.114\end{array}$ \\
\hline 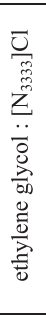 & $\begin{array}{l}\mathrm{r}^{2} \\
\text { RMSD } \\
\text { SSE (df) } \\
\text { AIC } \\
\text { P (F-test) } \\
\text { a, b }\end{array}$ & $\begin{array}{l}0.783 \\
- \\
9590.928(30) \\
215.772 \\
-\end{array}$ & $\begin{array}{l}0.797 \\
15.992 \\
8951.095 \\
216.310 \\
\text { vs CA: } 0.463 \\
\\
a=79.854\end{array}$ & $\begin{array}{l}0.799 \\
16.183 \\
8903.891 \\
219.352 \\
\text { vs CA: } 0.495 ; \\
\text { vs S/A: } 0.523 \\
a=65.891 ; \\
b_{D L}=-0.088\end{array}$ & $\begin{array}{l}0.866 \\
13.404 \\
5928.778 \\
208.175 \\
\text { vs CA: } 0.157 \\
\text { vs S/A: } 0.188 \\
\text { vs DL: } 0.830 \\
\mathrm{a}=-31766.216 \\
\mathrm{~b}_{1}=-64252.457 \\
\mathrm{~b}_{2}=32485.229\end{array}$ & $\begin{array}{l}0.783 \\
- \\
9579.092(30) \\
215.727 \\
-\end{array}$ & $\begin{array}{l}0.798 \\
15.987 \\
8945.239 \\
216.286 \\
\text { vs IA: } 0.464\end{array}$ & $\begin{array}{l}0.803 \\
16.015 \\
8720.788 \\
218.604 \\
\text { vs IA: } 0.474 ; \\
\text { vs S/A: } 0.511 \\
a=0.161 ; \\
b_{D L}=-475.226\end{array}$ & $\begin{array}{l}0.867 \\
13.343 \\
5875.060 \\
207.847 \\
\text { vs IA: } 0.152 ; \\
\text { vs S/A: } 0.183 ; \\
\text { vs DL: } 0.823 \\
a=-18459.990 \\
b_{1}=-37336.398 \\
b_{2}=18876.080\end{array}$ \\
\hline
\end{tabular}

$\mathrm{r}^{2}$ : coefficient of determination; RMSD: root-mean-square deviation; SSE (df): sum of squared errors of prediction (degrees of freedom between parenthesis); AIC: Akaike's information criterion; P (F-test) refers to the p-value of the F test that tests the null hypothesis that the errors of the respective deviation model are equal and the alternative hypothesis that they are higher than the errors of other deviations with less fitting parameters; $a, b_{1}, b_{2}, b_{D L}$ : estimated parameters, where 1 and 2 stand for the HBD and HBA, respectively. 
is the model best describing the mixture toxic behavior. The heavily negative value of "a" $(-468.005)$ indicates strong synergism, which is consistent with the pronounced concave shape of the isobologram (Fig. 1E). The heavily positive value of "b $\mathrm{HBA}_{\mathrm{HB}}$ " may indicate antagonism caused by the salt, which is observed at concentrations higher than $0.8 \mathrm{~g} \mathrm{~L}^{-1}$, approximately. On the other hand, the heavily negative value of " $\mathrm{b}_{\mathrm{HBD}}$ " confirms the synergistic interaction between DES components as visible in the isobologram, where the toxicity of the mixture is mainly caused by ethylene glycol (Table 2 , Fig. 1E).

Regarding ethylene glycol:[ $\left.\mathrm{N}_{3333}\right] \mathrm{Cl}$, the F-test to the errors did not highlight any deviation model as better describing the experimental data compared to the baseline model ( $P>0.05$; Table 2). However, the higher $\mathrm{r}^{2}$, supported by lower SSE and RMSD values suggest that the experimental data fit better to the CA or IA with DR deviation than to the baseline models. Despite the short differences between the statistical parameters, the IA model with DR deviation fits slightly better than its CA counterpart. Similarly to 1-

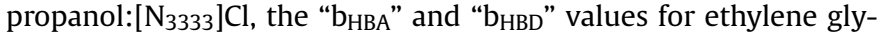
col: $\left[\mathrm{N}_{3333}\right] \mathrm{Cl}$ suggest antagonism caused by the salt, which is not depicted in the isobologram, as well as synergism mainly caused by the HBD is pictured by the strongly concave shape of the isoboles (Fig. 1F).

In summary, the toxicity of the tested DES was well described by the classical models of mixture toxicity, with the IA model with specific deviations being the one that adjusted better to the experimental data for 5 out of 6 DES investigated. The interactions (synergism and antagonism) found between DES components shows that DES toxicity cannot be predicted based solely on the toxicity of the starting materials. Moreover, this approach highlighted the role of both the HBD and HBA on DES toxicity, corroborating results of a previous study assessing DES toxicity to a bacterium (Wen et al., 2015). The HBA markedly affected DES toxicity, as translated by the higher toxicity of [ $\left.\mathrm{N}_{3333}\right] \mathrm{Cl}$-based DES compared to that of $\left[\mathrm{N}_{1111}\right] \mathrm{Cl}$ - and $\left[\mathrm{N}_{2222}\right]-\mathrm{Cl}$-based DES, this being related to decreased hydrophilicity of the HBA (de Morais et al., 2015). The pronounced synergism found for both $\left[\mathrm{N}_{3333}\right]$ Cl-based DES, but not for other DES, and the antagonism found for both $\left[\mathrm{N}_{1111}\right] \mathrm{Cl}$-based DES are also noteworthy in this context. A relevant role of HBD on DES toxicity has also been suggested in previous studies, namely concerning their cytotoxicity (Hayyan et al., 2016; Radošević et al., 2015; Wen et al., 2015) and toxicity to fungi and fish (Juneidi et al., 2016). Here, we found that ethylene glycol-based DES were equally or less toxic than 1-propanol-based DES (Table 1), which agrees with the differing toxicity of both these HBD isolated.

The knowledge of the type of interaction between the DES components (HBA and HBD) is of great importance for the toxicological profile of DES. The synergism is of particular concern, as the toxicity of the mixture (DES aqueous solution) is greater than the toxicity of each of its components separately, thus potentially more environmentally hazardous. In these cases, the toxicity of DES solutions would be underestimated if predicted based only on the toxicity of their components. In the present study, synergism was found for [ $\left.\mathrm{N}_{3333}\right] \mathrm{Cl}$-based DES and also for ethylene glycol:[ $\left.\mathrm{N}_{2222}\right]$ $\mathrm{Cl}$. The toxicity of $\left[\mathrm{N}_{3333}\right] \mathrm{Cl}$-based DES raises special concern, not only because of the strong synergism between their components (Fig. 1E and F), but also because of their high overall toxicity compared to the other DES (Table 1). However, it should be kept in mind that the response of different organisms to the same DES may vary (Wen et al., 2015). In other words, the fact that synergism (or antagonism) occurred between the components of a DES for a certain species does not mean that the same deviation will occur for other species. For this reason, from an environmentally precautionary perspective, studies covering several functional levels (e.g. Santos et al., 2015 for cholinium-based ILs) are essential to gain a comprehensive knowledge about the effects of these solvents on the aquatic ecosystems, thus improving the knowledge of their ecotoxicological profile and ultimately, leading to a more realistic environmental risk assessment of such chemicals.

\section{Conclusions}

Considering the tailor-made character of DES, the number of DES that can be created with the same starting materials is potentially countless, this making their toxicity assessment a daunting task. The appropriateness of mixture toxicity models to describe DES toxicity, as demonstrated for the first time in the present study, configures a breakthrough in this problematic. By feasibly modelling response surfaces of each DES (covering all theoretical combinations, i.e. molar ratios, between a given HBA and HBD) based on the experimental assessment of rationally selected ratios, one gains a broad overview of its toxicity profile, properly appraising interactive effects (synergism/antagonism; dose-level or dose-ratio dependence). Such predictive tools can be valuable to retrieve theoretical EC $x$ values that may hold as environmental benchmarks useful in the environmental risk assessment of new DES. Additionally, these tools provide the possibility of a priori selecting, among DES that fit the desired properties regarding functionality for a given application, those bearing lower environmental hazardous potential. In practice, the advantages of such a possibility reflect in two important arenas. First, regulation worldwide increasingly accounts to the environmental safety of newly developed compounds, specifically requesting the ecotoxicological assessment of chemicals (e.g. REACH Directive in Europe; EC, 2006), eventually comprising read-across (or data gap filling) frameworks (see e.g. ECHA, 2015; Williams et al., 2011 for an overview on this regulatory approach) for designer compounds such as DES. Secondly, important savings are likely to occur through preventing investment in the development of DES deriving from given HBD-HBA that are likely to be more environmentally hazardous, hence more hardly complying with mandatory regulation for the registration and marketing of new compounds.

\section{Acknowledgments}

Thanks are due for the financial support to CESAM - Centre for Environmental and Marine Studies, University of Aveiro, Portugal (UID/AMB/50017 - POCI-01-0145-FEDER-007638), to FCT - Portuguese Foundation for Science and Technology/MCTES - Ministry of Science, Technology and Higher Education, Portugal through national funds (PIDDAC), and the co-funding by the FEDER, within the PT2020 Partnership Agreement and Compete 2020. This work was also developed within the scope of the project CICECO-Aveiro Institute of Materials, University of Aveiro, Portugal, POCI-01-0145FEDER-007679 (FCT Ref. UID/CTM/50011/2013), financed by national funds through the FCT/MEC - Ministry of Education and Science, Portugal and when appropriate co-financed by FEDER under the PT2020 Partnership Agreement. The authors also acknowledge the support by the FCT through the project PTDC/ATPEAM/5331/2014, the doctoral grant of IPE Macário (SFRH/BD/ 123850/2016) and post-doctoral grants of AMM Gonçalves and JL Pereira (SFRH/BPD/97210/2013, SFRH/BPD/101971/2014), respectively. SPM Ventura acknowledges FCT for the contract IF/00402/ 2015. We are also grateful to Prof. António JA Nogueira for giving us permission to use the ToxCalcMix spreadsheet.

\section{Appendix A. Supplementary data}

Supplementary data related to this article can be found at https://doi.org/10.1016/j.chemosphere.2018.08.153. 


\section{References}

Altenburger, R., Backhaus, T., Boedeker, W., Faust, M., Scholze, M., Grimme, L.H., 2000. Predictability of the toxicity of multiple chemical mixtures to Vibrio fischeri: mixtures composed of similarly acting chemicals. Environ. Toxicol. Chem. 19, 2341-2347. https://doi.org/10.1002/etc.5620190926.

Backhaus, T., Faust, M., 2012. Predictive environmental risk assessment of chemical mixtures: a conceptual framework. Environ. Sci. Technol. 46, 2564-2573. https://doi.org/10.1021/es2034125.

Barata, C., Baird, D.J., Nogueira, A.J.A., Soares, A.M.V.M., Riva, M.C., 2006. Toxicity of binary mixtures of metals and pyrethroid insecticides to Daphnia magna Straus. Implications for multi-substance risks assessment. Aquat. Toxicol. 78, 1-14. https://doi.org/10.1016/j.aquatox.2006.01.013.

Burnham, K.P., Anderson, D.R., 2002. Model Selection and Multimodel Inference. A Practical Information-theoretic Approach, second ed. Springer-Verlag New York, Inc., p. 488

Cardellini, F., Germani, R., Cardinali, G., Corte, L., Roscini, L., Spretic, N., Tieccoab, M., 2015. Room temperature deep eutectic solvents of (1S)-(+)-10 camphorsulfonic acid and sulfobetaines: hydrogen bond-based mixtures with low ionicity and structure-dependent toxicity. RSC Adv. 40, 31772-31786.

Dai, Y., van Spronsen, J., Witkamp, G.J., Verpoorte, R., Choi, Y.H., 2013. Natural deep eutectic solvents as new potential media for green technology. Anal. Chim. Acta 766, 61-68. https://doi.org/10.1016/j.aca.2012.12.019.

Dai, Y., Witkamp, G.J., Verpoorte, R., Choi, Y.H., 2015. Tailoring properties of natural deep eutectic solvents with water to facilitate their applications. Food Chem 187, 14-19. https://doi.org/10.1016/j.foodchem.2015.03.123.

de Morais, P., Gonçalves, F., Coutinho, J.A.P., Ventura, S.P.M., 2015. Ecotoxicity of cholinium-based deep eutectic solvents. ACS Sustain. Chem. Eng. 3, 3398-3404. https://doi.org/10.1021/acssuschemeng.5b01124.

EC, 2006. Regulation (EC) 1907/2006 of the European Parliament and of Teh Council of 18 December 2006-REACH. Official Journal of the European Union. European Commission, 396:0001:0849:(EN: PDF). https://eur-lex.europa.eu/LexUriServ/ LexUriServ.do?uri1/40J:L:\%202006.

ECHA, 2015. Read-across Assessment Framework (RAAF). European Chemical Agency, Helsinki, Finland. https://doi.org/10.2823/546436.

Egorova, K.S., Ananikov, V.P., 2014. Toxicity of ionic liquids: eco(cyto)activity as complicated, but unavoidable parameter for task-specific optimization. ChemSusChem 7, 336-360. https://doi.org/10.1002/cssc.201300459.

Hammond, O.S., Bowron, D.T., Edler, K.J., 2017. The effect of water upon deep eutectic solvent nanostructure: an unusual transition from ionic mixture to aqueous solution. Angew. Chem. Int. Ed. 56, 9782-9785. https://doi.org 10.1002/anie.201702486.

Hayyan, M., Hashim, M.A., Al-Saadi, M.A., Hayyan, A., AlNashef, I.M., Mirghani, M.E.S., 2013a. Assessment of cytotoxicity and toxicity for phosphonium-based deep eutectic solvents. Chemosphere 93, 455-459. https://doi.org/ 10.1016/j.chemosphere.2013.05.013.

Hayyan, M., Hashim, M.A., Hayyan, A., Al-Saadi, M.A., AlNashef, I.M., Mirghani, M.E.S., Saheed, O.K., 2013b. Are deep eutectic solvents benign or toxic? Chemosphere 90, 2193-2195. https://doi.org/10.1016/j.chemosphere. 2012.11.004.

Hayyan, M., Looi, C.Y., Hayyan, A., Wong, W.F., Hashim, M.A., 2015. In Vitro and in Vivo toxicity profiling of ammonium-based deep eutectic solvents. PLoS One 10, 1-18. https://doi.org/10.1371/journal.pone.0117934.

Hayyan, M., Mbous, Y.P., Looi, C.Y., Wong, W.F., Hayyan, A., Salleh, Z., Mohd-Ali, O., 2016. Natural deep eutectic solvents: cytotoxic profile. SpringerPlus 5, 913 https://doi.org/10.1186/s40064-016-2575-9.

Huang, Z.L., Wu, B.P., Wen, Q., Yang, T.X., Yang, Z., 2014. Deep eutectic solvents can be viable enzyme activators and stabilizers. J. Chem. Technol. Biotechnol. 89, 1975-1981. https://doi.org/10.1002/jctb.4285.

Jhong, H.R., Wong, D.S.H., Wan, C.C., Wang, Y.Y., Wei, T.C., 2009. A novel deep eutectic solvent-based ionic liquid used as electrolyte for dye-sensitized solar cells. Electrochem. Commun. 11, 209-211. https://doi.org/10.1016/ j.elecom.2008.11.001.

Johnson, B., 2005. Microtox ${ }^{\circledR}$ Acute toxicity test. In: Small-scale Freshwater Toxicity Investigations, pp. 69-105. https://doi.org/10.1007/1-4020-3120-3_2.

Jonker, M.J., Svendsen, C., Bedaux, J.J.M., Bongers, M., Kammenga, J.E., 2005. Significance testing of synergistic/antagonistic, dose level-dependent, or dose ratio-dependent effects in mixture dose-response analysis. Environ. Toxicol. Chem. 24, 2701. https://doi.org/10.1897/04-431R.1.

Juneidi, I., Hayyan, M., Mohd Ali, O., 2016. Toxicity profile of choline chloride-based deep eutectic solvents for fungi and Cyprinus carpio fish. Environ. Sci. Pollut. Res. 23, 7648-7659. https://doi.org/10.1007/s11356-015-6003-4.

Latała, A., Stepnowski, P., Ne,dzi, M., Mrozik, W., 2005. Marine toxicity assessment of imidazolium ionic liquids: Acute effects on the Baltic algae Oocystis submarina and Cyclotella meneghiniana. Aquat. Toxicol. 73, 91-98. https://doi.org/10.1016/ j.aquatox.2005.03.008

Matzke, M., Arning, J., Ranke, J., Jastorff, B., Stolte, S., 2010. Design of inherently safer ionic liquids: toxicology and biodegradation. In: Handbook of Green Chemistry, pp. 233-298.

Mbous, Y.P., Hayyan, M., Hayyan, A., Wong, W.F., Hashim, M.A., Looi, C.Y., 2017a. Applications of deep eutectic solvents in biotechnology and bioengineering-promises and challenges. Biotechnol. Adv. 35, 105-134. https:// doi.org/10.1016/j.biotechadv.2016.11.006.

Mbous, Y.P., Hayyan, M., Wong, W.F., Looi, C.Y., Hashim, M.A., 2017b. Unraveling the cytotoxicity and metabolic pathways of binary natural deep eutectic solvent systems. Sci. Rep. 7, 41257. https://doi.org/10.1038/srep41257.

Motulsky, H., Christopoulos, A., 2004. Fitting Models to Biological Data Using Linear and Nonlinear Regression. A Practical Guide to Curve Fitting. GraphPad Software Inc., San Diego CA.

Nelson, D.L., Cox, M.M., 2012. Lehninger - Principles of Biochemistry, sixth ed. Freeman, W. H. \& Company.

Paiva, A., Craveiro, R., Aroso, I., Martins, M., Reis, R.L., Duarte, A.R.C., 2014. Natural deep eutectic solvents - solvents for the 21 st century. ACS Sustain. Chem. Eng. 2, 1063-1071.

Passos, H., Tavares, D.J.P., Ferreira, A.M., Freire, M.G., Coutinho, J.A.P., 2016. Are aqueous biphasic systems composed of deep eutectic solvents ternary or quaternary systems? ACS Sustain. Chem. Eng. 4, 2881-2886. https://doi.org/ 10.1021/acssuschemeng.6b00485.

Quinn, G.P., Keough, M.J., 2002. Experimental Design and Data Analysis for Biologists. Cambridge University Press, Cambridge, UK.

Radošević, K., Cvjetko Bubalo, M., Gaurina Srček, V., Grgas, D., Landeka Dragičević, T., Redovniković, R.I., 2015. Evaluation of toxicity and biodegradability of choline chloride based deep eutectic solvents. Ecotoxicol. Environ. Saf. 112, 46-53. https://doi.org/10.1016/j.ecoenv.2014.09.034.

Ruß, C., König, B., 2012. Low melting mixtures in organic synthesis - an alternative to ionic liquids? Green Chem. 14, 2969-2982. https://doi.org/10.1039/ b000000x.

Santos, J.I., Gonçalves, A.M.M., Pereira, J.L., Figueiredo, B.F.H.T., Silva, F.A.E., Coutinho, J.A.P., Ventura, S.P.M., Gonçalves, F., 2015. Environmental safety of olinium-based ionic liquids: assessing structure-ecotoxicity relationships. Green Chem. 17, 4657-4668. https://doi.org/10.1039/c5gc01129a.

Shah, D., Mjalli, F.S., 2014. Effect of water on the thermo-physical properties of Reline: an experimental and molecular simulation based approach. Phys. Chem. Chem. Phys. 16, 23900-23907. https://doi.org/10.1039/C4CP02600D.

Singh, B.S., Lobo, H.R., Shankarling, G.S., 2012. Choline chloride based eutectic solvents: magical catalytic system for carbon - carbon bond formation in the rapid synthesis of $\beta$-hydroxy functionalized derivatives. Catal. Commun. 24, 70-74. https://doi.org/10.1016/j.catcom.2012.03.021.

Stolte, S., Matzke, M., Jürgen, A., Böschen, A., Pitner, W.-R., Welz-Biermann, U., Jastorff, B., Ranke, J., 2007. Effects of different head groups and functionalised side chains on the aquatic toxicity of ionic liquids. Green Chem. 9, 1170-1179. https://doi.org/10.1039/b711119c.

UN, U.N., 2011. Globally Harmonized System of Classification and Labelling of Chemicals (GHS), fourth rev. ed. United Nations, New York and Geneva. https:// doi.org/10.1265/jjh.65.5

Vieira, V., Prieto, M.A., Barros, L., Coutinho, J.A.P., Ferreira, I.C.F.R., Ferreira, O., 2018. Enhanced extraction of phenolic compounds using choline chloride based deep eutectic solvents from Juglans regia L. Ind. Crop. Prod. 115, 261-271. https:// doi.org/10.1016/j.indcrop.2018.02.029.

Wen, Q., Chen, J.X., Tang, Y.L., Wang, J., Yang, Z., 2015. Assessing the toxicity and biodegradability of deep eutectic solvents. Chemosphere 132, 63-69. https:// doi.org/10.1016/j.chemosphere.2015.02.061.

Williams, E.S., Berninger, J.P., Brooks, B.W., 2011. Application of chemical toxicity distributions to ecotoxicology data requirements under REACH. Environ. Toxicol. Chem. 30, 1943-1954. https://doi.org/10.1002/etc.583.

Zhang, Q.H., Vigier, K.D., Royer, S., Jerome, F., 2012. Deep eutectic solvents: syntheses, properties and applications. Chem. Soc. Rev. 41, 7108-7146. https:// doi.org/10.1039/C2cs35178a.

Zhao, B.Y., Xu, P., Yang, F.X., Wu, H., Zong, M.H., Lou, W.Y., 2015. Biocompatible deep eutectic solvents based on choline chloride: characterization and application to the extraction of rutin from Sophora japonica. ACS Sustain. Chem. Eng. 3, 2746-2755. https://doi.org/10.1021/acssuschemeng.5b00619.

Zhekenov, T., Toksanbayev, N., Kazakbayeva, Z., Shah, D., Mjalli, F., 2017. Formation of type III Deep Eutectic Solvents and effect of water on their intermolecular interactions. Fluid Phase Equil. 441, 43-48. https://doi.org/10.1016/ j.fluid.2017.01.022. 